Conclusions Blood eosinophils and IgE levels may be regarded more as global predictors but FEV1 and FeNO may be considered more accurate predictors in risk assessment of future adverse events.

\section{EXHALED NITRIC OXIDE AS A PREDICTOR FOR EXACERBATION IN CHILDHOOD ASTHMA - IS IT USEFUL?}

doi:10.1136/archdischild-2012-302724.0670

'R Diaconu, 'L Stanescu, ${ }^{2} \mathrm{C}$ Diaconu. ${ }^{1}$ Pediatrics, University of Medicine and Pharmacy Craiova; ${ }^{2}$ Sports Medicine, Emergency County Hospital Craiova, Craiova, Romania

Aims Currently, the asthma control is based on symptoms and lung function indices. The inflammatory markers like exhaled nitric oxide (FeNO) may provide additional data for asthma management. We aimed to correlate the FeNO levels with asthma exacerbations in children admitted to our pediatric department.

Methods 104 children (57 boys), aged 5 to 11, were enrolled to our 12 month survey. The monthly follow up visits comprised in clinical exam, childhood asthma control test (C-ACT), spirometry and FeNO measurement (NioxMino, Sweden). The analysis was done using the chi squared test.

Results 68 children experienced a total of 114 exacerbations during the survey. Only 23 exacerbations were associated with positive FeNO values (over $25 \mathrm{ppB}$ ), compared to 67 C-ACT positive: $\mathrm{p}=0.000 ; \mathrm{OR}=0.17(0.09-0.31) ; 44$ spirometry positive: $\mathrm{p}=0.001$ $\mathrm{OR}=0.40(0.22-0.72)$ and 34 clinical positive findings: $\mathrm{p}=0.04$ $\mathrm{OR}=0.59(0.32-1.09) .21$ of the positive FeNO cases (91\%) had high values (over $50 \mathrm{ppB}$ ). On the other hand, 87 cases showed an increase in FeNO measurements without clinical exacerbation.

Conclusions Exhaled nitric oxide poorly correlates with asthma exacerbations, compared to "classical tools". High values may be useful as a predictor, but the sensitivity and specificity are still uncertain.

\section{EXHALED NITRIC OXIDE AND PULMONARY FUNCTION IN CHILDREN WITH ALLERGIC ASTHMA}

doi:10.1136/archdischild-2012-302724.0671

'A Omerčahïe Dizdareviç' ${ }^{2}$ S MesihoviéEinarević. 'Allergology, Rheumatology and Clinical Immunology; ${ }^{2}$ Cardiology, Children's Hospital Sarajevo, Sarajevo, Bosnia-Herzegovina

Background and Aims Nitric oxide (NO) is a marker of eosinophilic inflammation in airways and can be measured in exhaled air Fractional exhaled nitric oxide (FeNO) is elevated in allergic asthma. Children with asthma and normal spirometry (FEV1\%) can have an inflammation of airways. Inhaled steroid therapy decreases FeNO levels. The aims of this study is to analyze the values of FeNO and FEV1\% in children with allergic asthma (steroid naïve and undertaking inhaled steroid therapy).

Methods Thirty steroid naïve children with asthma, aged 5-15 years ( $<10$ years $n=20,>10$ years $n=10)$ and thirty children with asthma, undertaking inhaled steroid therapy longer than 1 month, aged $5-15$ years $(<10$ years $18,>10$ years 12$)$, were included. Recent respiratory infections were negative in all groups. On line technique was performed in measuring FeNO using a cheiloiluminescent analyser Niox, Aerocrine-Sweden, according to ERS/ATS recommendations. Spirometry was performed by standardized procedure.

Results FeNO levels were significantly higher (Kruskal-Wallis test) in steroid naïve group $(\mathrm{C}=47.45)$ vs undertaking therapy group $(C=11.15)$. Significant difference between these groups (Mann-Whitney test) was confirmed( $Z=6.56$; $p=0,0001) .98 \%$ children in steroid naïve group had normal spirometry (FEV1\%>80\%). Significant difference in FEV1\% (Mann-Whitney test), between steroid naïve and undertaking therapy group, was found $(Z=-3.86 ; p=0.0001)$.

Conclusions Steroid naive children with asthma had significant higher values of FeNO vs children undertaking inhaled steroid therapy. Significant difference in FEV1\% was found in these two groups. In our study, steroid naive children with asthma and normal FEV1\% had eosinophilic inflammation in airways.

\section{FENO AND ASTHMA CONTROL}

doi:10.1136/archdischild-2012-302724.0672

F Cora, M Moiceanu, E Buzoianu, V Hurduc, DA Plesca. Pediatrics, Children's Hospital 'Dr.Victor Gomoiu', Bucharest, Romania

Background and Aims Asthma is a chronic inflammatory disease of the lower airways, whose treatment is conducted by guidelines in use, depending on clinical markers of disease control (ACT=asthma control test score) and spirometric values. Due to situations in which there is discrepancy between the two categories of parameters, we aimed this study to examine whether FENO measurement may be an additional argument in guiding the treatment.

Method The prospective study lasted five months and included 30 patients diagnosed as moderate persistent asthma, aged 5-17 years, nonsmokers; ACT score, FEV1 and FENO were assessed.

Results 12 patients had ACT> 19, normal FEV1 values and FENO $<20 \mathrm{ppb}$.

18 patients had ACT < 19; 9 of them had normal FEV1 values and 16 had FENO values $>32 \mathrm{ppb}$

Conclusion FENO value correlates better than FEV1 with clinical asthma control score, so it can be an additional marker in therapeutic decision.

\section{PRE AND POST BRONCHODILATOR AIRWAY RESISTANCE VALUES IN CHILDREN WITH ASTHMA USING AIRFLOW PERTURBATION DEVICE (APD)}

doi:10.1136/archdischild-2012-302724.0673

${ }^{1,2} \mathrm{~N}$ Rostami, ${ }^{3} \mathrm{M}$ Bautista, ${ }^{4} \mathrm{~A}$ Johnson, ${ }^{5} \mathrm{~J}$ Vossoughi, ${ }^{6} \mathrm{M}$ Kezsler. 'Pediatrics, Georgetown University Hospital, Washington, DC: ${ }^{2}$ Pediatrics, Sinai Hospital, Baltimore, Baltimore, MD; ${ }^{3}$ Pediatrics, Georgetown University Hospital, Washington DC, DC; ${ }^{4}$ Bioengineering, University of Maryland, College Park; ${ }^{5}$ Engineering, Engineering and Scientific Research Associates, Olney, MD; ${ }^{6}$ Pediatrics, Brown University, Women and Infants Hospital, Providence, RI, USA

Background Asthma is the most common chronic disease of childhood and pulmonary function testing plays an important role in assessment and management of children with asthma. Pre and post bronchodilator spirometry test is the most common pulmonary function measurement that is utilized in the diagnosis of asthma.

Methods Respiratory resistance using APD was measured prior and 20 minutes after Albuterol in children with asthma who presented to the Pediatric Pulmonary Clinic at GUH.

Results A total of 30 children with asthma (mean age: 10.6; range: 5.6-17) including 14 female and 16 male participated in the study. The respiratory resistance values by APD ranged from 3.34-8.22 $\mathrm{CmH} 2 \mathrm{O} / \mathrm{L} / \mathrm{S}$ (mean 5.27) for pre bronchodilator treatment and 2.37-6.95 (mean 4.33) for post treatment. All 30 children showed decrease in respiratory resistance as measured by APD after bronchodilator therapy. The highest value of resistance was 8.22 which was seen in the youngest child (5.6 yo) and the lowest resistance was 3.34 which was seen in an older child (16 yo). These results are consistent with the findings that airway resistance decreases after bronchodilator therapy in patients with asthmahas been developed to measure airway resistance noninvasively and without need of extensive coordination. The APD is a simple and portable device that can be used easily by patients of all ages.

Conclusions APD is a simple, convenient, effortless, and easy to use device that may be a used as a valuable tool in evaluation of children with asthma.

This abstract is funded by NIH-NHLBI Grant \# 2R44HL0780 55-02A1 